\title{
THE NUMBER OF GENES ON THE SECOND CHROMOSOME OF DROSOPHILA MELANOGASTER AND A COMMENT ON THE GENETIC STRUCTURE OF EUKARYOTES
}

\author{
J. A. BISHOP, CAROL KEILL and M. R. MACNAIR* \\ Department of Genetics, University of Liverpool, Liverpool L69 3BX
}

Received 4.viii.80

\begin{abstract}
SUMMARY
Recessive lethals on the second chromosome were extracted from genetically isolated populations in Australia and the U.K. The frequency of allelism, used in a manner analogous to capture-recapture of animal populations, indicated that the number of genes capable of mutating to lethal had a 95 per cent probability of being in the range 247 to 1140 , although excluding possibie heterotic and synthetic lethals altered this to 309 to 3568 . Possible sources of bias are discussed. The disagreement between these values and those obtained the direct measurements of DNA (more than 10 times greater) is clear. It is suggested that many of the genes of eukaryotes have been duplicated by unequal exchange during recombination and occur in functionally related groups or in supergenes. Some consequences of this hypothesis to population genetics are noted.
\end{abstract}

\section{INTRODUCTION}

THERE is enough DNA in the eukaryote genome to form a very large number of genes or cistrons. Measurements indicate that there is sufficient in Drosophila melanogaster for 100,000 genes of 1000 base pairs and for 16-20 times this number in man (Laird and McCarthy, 1969; Ris and Kubai, 1970). Not all eukaryotic DNA however codes a genetic message, so such figures are over-estimates. Peacock et al. (1974) found, for instance, that about 22 per cent of the genome of $D$. melanogaster is made up of highly repetitive DNA sequences that do not seem to be translated and whose function is not yet understood.

An alternative and contradictory picture emerges from consideration of mutation rate in man (see, for instance, Krone and Wolf, 1978) and Drosophila pseudoobscura (Dobzhansky and Wright, 1941) and from investigation of the distribution of recessive lethal mutations induced in certain small parss of the genome of $D$. melanogaster. The number of such genes could be at least an order of magnitude lower than the figure suggested by DNA measurements. Judd et al. (1972) and Schalet and Lefevre (1976) have made detailed studies of short segments of the $\mathrm{X}$ chromosome; Hochman (1976) has investigated chromosome 4 (the microchromosome) and Garcia-Bellido and Ripoll (1978) have investigated variation within a number of chromosomal deficiencies on several chromosomes. This work suggests that the species possesses about 5000 genes and it gives tentative support to the one gene $=$ one band hypothesis. This implies that one major

\footnotetext{
* Present address: Department of Biological Sciences, University of Exeter, Exeter EX4 4QG
} 
gene, which Judd (1976) suggests might be a complex locus, may equate to one of the bands observed on the giant polytene chromosomes. There are several well recognised objections to these latter experiments, some of which are carefully discussed by rheir authors. One problem is that they concentrate, for obvious practical reasons, on artificially induced mutation in tiny and arbitrarily selected parts of the genome. These mutants and regions may, for unknown reasons, be atypical of the whole. The experiment described here attempts to overcome this problem by studying naturally occurring mutations of a substantial part of the genome of $D$. melanogaster in widely dispersed natural populations. The object of our study was the entire second chromosome; the two hypotheses indicate that this has either about $(100,000 \times 0 \cdot 78) \times 0 \cdot 4=31,200$ genes (allowing for repetitive DNA and the size of the chromosome) or about 2000 complex loci.

\section{THE EXPERIMENT}

Two genetically isolated populations of $D$. melanogaster were required so that all mutants recovered from them could be regarded as the products of independent random events. A long established population in a large greenhouse at Liverpool, U.K., that showed considerable genetic heterogeneity and which was probably introduced in fermenting fruit used as a source of food for butterflies, and one at the Chateau Tahbilk winery in Australia (McKenzie, 1974) appeared to fulfil this condition. Two series of recessive second chromosome lethals, one from each population, were collected. A number of separate samples were taken but care was taken to ensure that a series of mutants from one population did not contain replicates of the same lethal. This laborious process, involving many thousands of crosses, also provided data concerning the ecological and population genetics of the mutants that will be considered separately. All mutants were isolated by the $C y P m$ method (see Lewontin, 1974) and stored balanced against the $C y$ chromosome. The sample from one population was crossed to the sample from the other. All instances of possible complementation were at least triple checked to ensure that bias due to non-virginity of females was reduced to a minimum. Stocks were kept in $200 \mathrm{ml}$ milk bottles and crosses performed in glass tubes. The medium was a dead yeast/sugar mixture in agar and the incubation temperature was $25^{\circ} \mathrm{C}$.

The probability that a lethal mutation occurs at a locus in the Liverpool sample is $N_{1} / P$ when $N_{1}$ is the number of loci sampled and $P$ is the unknown number of genes on the chromosome. Similarly, the probability for the Chateau Tahbilk population is $N_{2} / P$. Thus the probability that a mutation of the same locus is present in both samples of lethals is $N_{1} N_{2} / P^{2}$. The observed number of lethals common to the two populations, $M$, is an estimate of $P \times N_{1} N_{2} / P^{2}$, so the two may be equated and $P$ estimated as:

$$
P=\frac{N_{1} N_{2}}{M}
$$

This is the Lincoln Index of population ecology (Blower et al., 1981). For two sample estimations of $P$ the methods based on the increase in fraction marked (or known) and the change in ratio of marks, discussed by Blower et $a l$, reduce to this form. Blower et al. also give the methods used to calculate 
the standard error and approximate confidence limits for the population estimate. An alternative maximum likelihood method of estimating the number of loci capable of mutating to lethal, based on the number of loci capable of mutating to lethal, based on the number of classes present in a sample of independently derived lethals, is given by Lewontin and Prout (1956). It has been used to estimate $P$ from the data of Wallace (1950) and Dobzhansky and Wright (1941), (table 1). This model is not applicable to the present data.

TABLE 1

Number of loci capable of mutating to lethal

\begin{tabular}{|c|c|c|c|}
\hline Species & $\begin{array}{c}\text { Chromosome } \\
\text { studied }\end{array}$ & No. of locit & Reference \\
\hline D. melanogaster & II & $405 \& 568$ & Present study \\
\hline D. melanogaster & II & $\left.\begin{array}{l}400 \\
342\end{array}\right\} *$ & $\begin{array}{l}\text { Wallace (1950) } \\
\text { Lewontin and Prout (1956) }\end{array}$ \\
\hline D. melanogaster & II & 495 & Ives $(1945)$ \\
\hline D. willistoni & II & 1063 & Pavan and Knapp (1954) \\
\hline D. pseudoobscura & III & $\left.\begin{array}{l}289 \\
268\end{array}\right\} *$ & $\begin{array}{l}\text { Dobzhansky and Wright (1941) } \\
\text { Lewontin and Prout (1956) }\end{array}$ \\
\hline
\end{tabular}

$\dagger$ Note that the 95 per cent confidence limits of these estimates, when they can be estimated, are large and highly asymmetric. For instance, in this study, the limits are 247-1140 and 309-3568.

${ }^{*}$ Estimates by differing methods from the same data.

Our estimate is based on a comparison of chromosomes, while strictly speaking $N_{1}$ and $N_{2}$ should represent numbers of loci. Since any one lethal-bearing chromosome could carry more than one lethal, $N_{1}$ and $N_{2}$ will in fact be underestimates of the number of loci compared. Previous authors (Dobzhansky and Wright, 1941; Wallace, 1950) have attempted to correct this error by estimating the number of chromosomes carrying more than one lethal from the Poisson distribution. We have not attempted such a correction because during our study we were able to detect some chromosomes that carried multiple lethals, but do not know what proportion of the total these represent. Our estimate will therefore be conservative, but the error involved is unlikely to be large.

\section{REsults}

About 74 lethal chromosomes were extracted from the Liverpool population and a series of allelism tests revealed that these represented 47 different lethal genes. More than 90 lethal chromosomes representing 69 different loci were taken from the population at Chateau Tahbilk. Eight lethals were common to both populations. Thus the number of loci capable of mutating to lethal $(P)$ is estimated as

$$
P=\frac{47 \times 69}{8}=405
$$


TABLE 2

Lethal second chromosomes of Drosophila melanogaster from Liverpool and Chateau Tahbilk

Local laboratory codes for chromosomes have prefixes B, C, D, E and GG (Liverpool) and $\mathrm{T}, \mathrm{V}$ and $\mathrm{Y}$ (Chateau Tahbilk).

(a) Four chromosomes were recovered once from Liverpool and Chateau Tahbilk.

(b) A number of chromosomes were recovered from both populations. They were also sampled more than once from one or the other of the populations. Complementation tests indicated that they fell into two groups:

\begin{tabular}{|c|c|c|c|c|c|}
\hline \multirow[b]{2}{*}{ Locus } & \multicolumn{3}{|c|}{ Group 1} & \multicolumn{2}{|c|}{ Group 2} \\
\hline & A & B & C & D & $\mathrm{E}$ \\
\hline & V3 & V3 & V3 & D6 & D6 \\
\hline & T27 & T27 & & GG3 & $\mathrm{C} 16$ \\
\hline & & V13 & V13 & D7 & B25 \\
\hline & GG2 & & V15 & D8 & Y19 \\
\hline & & & $\mathrm{C} 10$ & E90 & \\
\hline & & & & B9 & \\
\hline & & & & Y17 & \\
\hline
\end{tabular}

This tabulation suggests the hypothesis that, of the five loci A-E postulated, four are common to the two populations. Further examination (Bishop, Haslock and Keill, in preparation) indicates that chromosome D6 in group 2 does carry at least two lethal loci. The situation in group 1 is complex and some, but not all, of the chromosomes it contains are synthetic lethals.

with approximate 95 per cent confidence limits of 247 and 1140 . Four of the lethals were recovered once from each population. The remaining four were sampled several times from one or the other locality (table 2). The most obvious hypothesis to explain these data is that the two groups noted carry five lethal loci. Thus strain V3 has three lethals (A, B and C) of which two (A and B) are common to T27 and B and C are found in V13 etc. This interpretation, though consistent with the data, is unsatisfactory; several strains in group one behave as synthetic lethals. Previous studies (see Lewontin, 1974) indicate that these are uncommon and indecd group 1 contains the only ones that we have yet detected (Bishop, Haslock and Keill, in preparation).

The high frequency of recapture of members of groups 1 and 2 (table 1) is not by itself surprising. In computer simulations we find that frequencies of recessive lethals of as high as four per cent occur in populations of 1000 individuals. Genes at such frequencies would be expected to be sampled more than once. Their existence in both populations might indicate that they are, in some way, heterotic. If they are, the assumption that all lethals have an equal probability of being sampled, which underlies the estimate, would be violated. We can remove these four suspect "recaptures" (i.e., GG2, C10, Y17, Y19 and their relatives) from consideration. Our estimate of $P$ then becomes

$$
P=\frac{43 \times 65}{4}=699
$$

with confidence limits of 358 and 14,444 . These broad limits are an artefact of the small size of $M$; if an additional recapture is assumed $\left(N_{2}=66, M=5\right)$ $P$ becomes 568 with 95 per cent confidence limits of 309 and 3568 . If the 
additional lethal is assumed to be in the Liverpool sample these figures are slightly higher. This process (Bailey's correction, see Blower et al., 1981) also has the effect of reducing the upward bias of the Lincoln Index likely to occur when values of $M$ are small.

\section{Discussion}

The results support the hypothesis from lethal saturation, and DNA investigation (Baker and Thomas, 1977) that there are a relatively small number of genes in Drosophila and, on chromosome 2 less than the figure suggested by the one gene $=$ one band hypothesis. The accuracy of our estimate, however, depends on a series of interrelated assumptions (Blower et al., 1980). Our selection of mutants must be a simple random selection of all those that are possible. It may, for instance, be less likely that we shall isolate a lethal associated with a mutation rate of $1 \times 10^{-7}$ than one associated with a rate of $1 \times 10^{-5}$. However, both populations from which the variation was originally isolated are finite in size $\left(N_{e}\right.$ is approximately 1000 for the Liverpool population) so the frequency of a lethal allele is more likely to be inflenced by chance than by such rates (e.g., Crow and Kimura, 1972, p. 445). In a simulation of a population of size 1000, and with 100 loci capable of mutating to lethal, 50 with a mutation rate $(\mu)$ of $10^{-4}$ and 50 with $\mu=10^{-6}$, there was no discernible difference between the frequency of occurrence of lethals in the two groups.

A major source of bias would arise if some of the mutants examined were heterotic and so were maintained at higher frequencies than one would otherwise expect. The effect would be similar to that caused by the phenomenon of trap addiction in population studies and would cause $P$ to be underestimated (Bishop and Sheppard, 1974). As noted in Results we have attempted to allow for this by using all apparent recaptures to obtain one of the estimates of $P$; the synthetics and possible heterotics being excluded from the other.

Not all loci are likely to mutate to a lethal phenotype under the conditions of environment provided. Hochman (1976) in his exhaustive study of chromosome 4 found 37 vital loci and a further 6-8 for recessive visible characters. If a similar ratio of the two types of loci exists for chromosome 2 then $P$ underestimates the total number of genes by 14-18 per cent. During further investigation we have indeed noted that some chromosomes, lethal under our conditions, survive in richer media (Bishop, Haslock and Keill, in preparation).

The number of genes capable of mutating to lethal has been estimated previously for various Drosophila species by methods related to the one proposed (table 2). However, they assume that lethals are of independent origin; in not all these studies is this assumption necessarily met and in a finite population there will be identity by descent. Ives (1945) collected his lethals from the same population, while Dobzhansky and Wright (1941) and Wright, Dobzhansky and Hovanitz (1942) compared mutants obtained from various populations in California. Jones and Parkin (1977), after noting the extensive movement of $D$. pseudoobscura observed in capture-recapture experiments, concluded that the population of this species in North America may be a single interbreeding unit. The same criticism could apply to the lethals studied by Pavan and Knapp (1954), who compared those from 13 
different populations of $D$. willistoni in Brazil. All the studies, however, agree on an order of magnitude for $P$, the number of genes capable of mutating to lethal on chromosomes of these Drosophila species.

There is increasing evidence from eukaryotes to indicate that an assumption of a relatively small number of genes is not unreasonable. Ohno (1970) proposed that gene duplication is an important event in evolution. Many human genes are organised into groups representing the outcome of gene duplication. There are at least eight conventional cistrons in two complex "genes" or supergenes involved in production of globin molecules that go into the production of the several human haemoglobins (Weatherall et al., 1979). This does not include the myoglobin locus from which they were originally derived by duplication and from which they have since functionally diverged or the genes controlling the production of the various polypeptides also in the supergene (Van Der Ploeg et al., 1980). Harris (1979) notes that 50 per cent of the structural loci coding for human enzyme proteins are duplicated. Many of these duplicated loci are unlinked and it is not known whether they were duplicated in "one fell swoop by tetraploidization" or by separate duplication events. There is good evidence for separate duplication, probably by unequal crossing over, in globin genes, the HLA complex of man (and its equivalent in other animals), the complement system, and the immunoglobulin complex (e.g., Bodmer, 1979). Extreme examples of multiple duplications are found in cell cultures from the mouse exhibiting resistance to methotrexate (Walker, 1979) and in aphids (Myzus persicae) resistant to insecticides (Devonshire and Sawicki, 1979). These may be atypical cases but they do represent genetic responses to strong selective pressures. We would suggest that the modal number of products of duplication is about 10 , some DNA being unduplicated while other sequences are multiplied tens or even hundreds of times. Our lethals would be more likely to be either deletions or mutations of controlling elements, rather than point mutations of individual cistrons. Deletions will obviously be produced as the reciprocal product to duplication after imperfect pairing of chromatids during meiosis. Such mutation can be as frequent as base substitution (e.g., Gelbart and Chovnick, 1979). In an outbreeding diploid organism such as $D$. melanogaster or man, these scars of previous duplications will be preserved for a considerable number of generations.

There may have been an orderly progression from prokaryote to eukaryote organization of the genome. Evidence for this from many studies involving protein and DNA sequencing is accumulating. Duplications of course, are well known in prokaryotes but the genetic complexities involved in development and differentiation which produce an organism responding to a wide range of environmental conditions, are best demonstrated in the eukaryotes. To take a specific example, heterozygous advantage, such as "that tired old Bucephalus, sickle cell anaemia" (Lewontin, 1974) or warfarin resistance in rats (Bishop et al., 1977), becomes the manifestation of an intermediate stage in achieving a more perfect adaptation. It is therefore a transient phenomenon and as a result, rare. If, for example, the gene from human $\beta$ globin was duplicated in an African population polymorphic for the $A$ and $S$ alleles, a new supergene containing the normal and the mutant loci could be formed. Fixation of the new supergene due to the superiority of the cis-heterozygote in a malarial environment would be 
rapid. This process, envisaged by Spofford (1969) and discussed in an evolutionary context by Mayo (1970), would quickly reduce any segregational load to negligible significance.

All stages in identity of gene duplications could occur. Complete identity would be difficult to identify except by direct investigation of DNA, though detailed clinical studies did reveal duplication of the human $\alpha$ globin loci subsequently confirmed by study of DNA (Weatherall et al., 1979; Lauer et al., 1980). Near identity could be confused with true allelism unless thorough genetic investigations were performed. True electrophoretic alleles are frequent, for instance in human $\beta$ globin where the most famous example is that associated witlı haemoglobin S. Chymotrypsinogen A, B and $C$ (inactive precursors of chymotrypsin) in cattle are electrophoretically separable, and are probably coded by recently duplicated genes (Hartley, $1970,1979)$. Some duplications will remain as integrated supergenes such as the $\varepsilon-\mathrm{G}_{\gamma}-\mathrm{A}_{\gamma}-\delta-\beta$ globin complex in man. Others will diverge structurally and chromosomally and even functionally. There are obvious structural relationships between the serine protease enzymes trypsin, the chymotrypsins, elastase and factor IX, factor $\mathrm{X}$ and thrombin, but the first three are digestive enzymes while the latter three are clotting factors involved in the final stage of blood coagulation (Hartley, 1970, 1979). The actin genes of Drosophila are dispersed widely over the chromosomes (Fyrberg et al., 1980). Protein and isoenzyme variation will thus reflect the existence of a heterogeneous group of phenomena:

(1) true allelism

(2) differences between very similar tandemly duplicated or palindromic cistrons

(3) polymorphism for control of tandemly duplicated genes (Bodmer, 1979).

If this hypothesis has any truth, our ideas about neutral mutations, polymorphism, genetic load and the evolution of dominance will need to be reassessed.

Acknowledgements. - We are grateful to D. A. Ritchie and P. Strike for discussion and to L. M. Cook, O. Mayo and N. K. Todd who commented on the manuscript. J. McKenzie generously provided the material from Chateau Tahbilk in Australia.

\section{REFERENCES}

BAKER, R. F., AND THOMAS, C. A. 1977. The origin and complexity of inverted repeat DNA sequences in Drosophila. In DNA Insertion Elements, Plasmids and Episomes, eds. A. I. Bukhari, J. A. Shapiro and S. L. Adhya, pp. 463-469. Cold Spring Harbor Laboratory. BISHOP, J. A., HARTLEY, D. J., AND PARTIDGE, G. G. 1977. The population dynamics of genetically determined resistance to warfarin in Rattus norvegicus from mid Wales. Heredity, 39, 389-398.

BISHOP, J. A., AND SHEPPARD, P. M. 1974. An evaluation of two capture-recapture models using the technique of computer simulation. In The Mathematical Theory of the Dynamics of Biological Populations, eds. M. S. Bartlett and R. W. Hiorns, pp. 235-252. Academic Press, London and New York.

BLOWER, J. G., COOK, L. M., AND BISHOP, J. A. 1981. Estimating the Size of Animal Populations. George Allen and Unwin, London.

BODMER, W. F. 1979. Gene clusters and the HLA system. In Human Genetics: Possibilities and Realities, CIBA Foundation Symposium 66 (new series), pp. 205-223. Elsevier/North Holland, Amsterdam and New York. 
CROW, J. F., AND Kimura, M. 1972. An Introduction to Population Genetics Theory. Harper and Row, New York.

DEVONSHIRE, A. L., AND SAWICKI, R. M. 1979. Insecticide-resistant Myzus persicae as an example of evolution by gene duplication. Nature (London) 280, 140-141.

DOBZHANSKY, TH., AND WRIGHT, S. 1941. Genetics of natural populations. V. Relations between mutation rate and accumulation of lethals in populations of Drosophila pseudoobscura. Genetics, 26, 23-51.

FYRBERG, E. A., KINDLE, K. L., DAVIDSON, N., AND SODJA, A. 1980. The actin genes of Drosophila: a dispersed multigene family. Cell, 19, 365-378.

GARCIA-BELlido, A., AND RIPOLL, P. 1978. The number of genes in Drosophila melanogaster. Nature, London, 273, 399-400.

GELBART, W.M., AND CHOVNICK, A. 1979. Spontaneous unequal exchange in the rosy region of Drosophila melanogaster. Genetics, 92, 849-855.

Hartley, B.S. 1970. Homologies in serine proteinases. Phil. Trans. Roy. Soc. Lond. B., 257, $77-87$.

HARTLEy, B. S. 1979. Evolution of enzyme structure. Proc. Roy. Soc. Lond. B., 205, 443-452.

HARRIS, H. 1979. Multilocus enzymes in man. In Human genetics: possibilities and realities. CIBA foundation symposium 66 (new series) pp. 187-199. Elsevier/North Holland, Amsterdam and New York.

HOCHMAN, B. 1976. The fourth chromosome of Drosophila melanogaster. In The Genetics and Biology of Drosophila, eds. M. Ashburner and E. Novitski, Vol. 1b, pp. 903-928. Academic Press, London and New York.

IVES, P. T. 1945. The genetic structure of American populations of Drosophila melanogaster. Genetics, 30, 167-196.

IONES, J. S., AND PARKIN, D. T. 1977. Attempts to measure natural selection by altering gene frequencies in natural populations. In Measuring Selection in Natural Populations. Eds. F. B. Christiansen and T. M. Fenchel, Lecture Notes in Biomathematics 19,83-96. SpringerVerlag, Berlin, Heidelburg and New York.

JUDD, B. H., SHEN, M. W., AND KAUFMAN, T. C. 1972. The anatomy and function of a segment of the X chromosome of Drosophila melanogaster. Genetics, 71, 139-156.

JudD, B. H. 1976. Genetic units of Drosophila-complex loci. In The Genetics and Biology of Drosophila, eds. M. Ashburner and E. Novitski, Vol. 1b, pp. 767-799. Academic Press, London and New York.

KRONE, W., AND WOLF, U 1978. Chromosomes and protein variation. In The Biochemical Genetics of Man, eds. D. J. H. Brock and O. Mayo, 2nd ed. pp. 93-154. Academic Press, London and New York.

LAUER, J., SHEN, J. C.-K., AND MANIATIS, T. 1980. The chromosomal arrangement of human $\alpha$-like globin genes: sequence homology and $\alpha$-globin deletions. Cell, 20, 119-130.

LAIRD, C. D., AND McCARTHY, B. J. 1969. Molecular characterisation of the Drosophila genome. Genetics, 63, 865-882.

LEWONTIN, R. C. 1974. The Genetic Basis of Evolutionary Change. Columbia University Press, New York and London.

LEWONTIN, R. C., AND PROUT, T. 1956. Estimation of the number of different classes in a population. Biometrics, 12, 211-223.

McKENZIE, J. A. 1974. The distribution of vineyard populations of Drosophila melanogaster and Drosophila simulans during vintage and non-vintage periods. Oecologia (Berl.), 15 , $1-16$.

MAYO, O. 1970. The role of duplications in evolution. Heredity, 25, 543-553.

OHNO, s. 1970. Evolution by Gene Duplication. Springer, Berlin.

PAVAN, C., AND KNAPP, E. N. 1954. The genetic population structure of Brazilian Drosophila willistoni. Evolution, 8, 303-313.

PEACOCK, W. J., BRUTLAG, D., GOLDRING, E., APPELS, R., HINTON, C. W., AND LINDSLEY, D. L. 1974. The organisation of highly repeated DNA sequences in Drosophila melanogas ter chromosomes. Cold Spring Harbor Symposium in Quantitative Biology, 38, 405-416.

RiS, H. AND KUBAI. D. F. 1970. Chromosome structure. Ann. Rev. Genet., 4, 263-294.

SCHALET, A., AND LEFEVRE, G. 1976. The proximal region of the $\mathrm{X}$ chromosome. In The Genetics and Biology of Drosophila, eds. M. Ashburner and E. Novitski, Vol. 1b, pp. 847-902. Academic Press, London and New York.

SPOFFORD, J. B.. 1969. Heterosis and the evolution of duplications. Am. Nat., 103, 407-432. VAN DER PLOEG, L. H. T., KONINGS, A., OORT, M., ROOS, D., BERNINI, L., AND FLAVELL, R. 1980. $\gamma$ - $\beta$-Thalassaemia studies showing that deletion of the $\gamma$-and $\delta$-genes influences $\beta$-globin gene expression in man. Nature (London), 283, 637-642. 
WALKER, P. M. B. 1979. Genes and non-coding DNA sequences. In Human Genetics: Possibilities and Realities. CIBA foundation symposium 66 (new series), pp. 25-38. Elsevier/North Holland, Amsterdam and New York.

WALLACE, B. 1950. Allelism of second chromosome lethals in Drosophila melanogaster. Proc. Nat. Acad. Sci. U.S., 36, 654-657.

WEATHERALL, D. J., CLEGG, J. B., WOOD, W. G., AND PASVOL, G. 1979. Human haemoglobin genetics. In Human Genetics: Possibilities and Realities. CIBA foundation symposium 66 (new series) pp. 147-174. Elsevier/North Holland, Amsterdam and New York.

WRIGHT, S., DOBZHANSKY, TH., AND HOVANITZ, W. 1942. Genetics of natural populations. VII. The allelism of lethals in the third chromosome of Drosophila pseudoobscura. Genetics, 27, 363-394. 